\title{
A representação do "eu" na interação com o "outro": uma análise do documentário Edifício Master, de Eduardo Coutinho (1)
}

\author{
Marine Souto Alves e Cláudio do Carmo Gonçalves
}

\begin{abstract}
Resumo:
O presente trabalho estabelece uma leitura do documentário Edifício Master, de Eduardo Coutinho a partir da idéia traçada por Erving Goffman a respeito da representação que desempenhamos de nós mesmos na interação com o outro. Para tanto, procuraremos observar como as pessoas se re-inventam diante da câmera, pensando tanto na interação face to face dessas pessoas com o cineasta e sua câmera, como a interação indireta com o público espectador. Assim também, buscaremos entender como a relação entre o real e o ficcional é articulada no filme, tanto pelas performances dos personagens quanto pelo próprio diretor e equipe de produção do documentário, os responsáveis pela criação de uma "realidade fílmica". Nesse ínterim, procuraremos refletir sobre as questões que envolvem a produção de um filme documentário, com base, principalmente, nas teorias trabalhadas por Bill Nichols.
\end{abstract}

\section{Palavras Chave:}

Representação, documentário, real e ficcional, interação social.

\section{Abstract:}

This paper proposes an analysis on Eduardo Coutinho's documentary Edifício Master, according to Erving Goffman's statements about self representation conditions on the ways of interaction with the other ones. We observe how people re-invent themselves in front of the camera, in order to interact face to face with the filmmaker and the camera itself, such as in order to interact indirectly with the audience. We aim also to understand the relation between fiction and non-fiction in the film process, just about personage's performances as much as filmmaker's and production team's performances on the way to produce a "the truth of the film". We try to reflect about questions on documentary films productions from, mainly, Bill Nichol's theorizing.

\section{Keywords:}

self representation, documentary, fictions and non-fiction, social interaction.

\section{Introdução}

Num processo de interação social, quando um sujeito encontra-se na presença de outros, estes buscam alcançar a maior quantidade de informações a seu respeito ou utilizam-se das que já possuem. Seus interesses recaem sobre sua situação sócio-econômica, o que pensa sobre si mesmo, a confiança que merece, entre outras coisas. Estas informações convêm para definir a situação interativa, assim, poderão agir para obter desse sujeito uma resposta desejada. Para os presentes, muitas serão as fontes de 
informações disponíveis, a exemplo da conduta e da aparência do indivíduo. (GOFFMAN, 1999: 11).

E. Goffman defende a idéia de que o homem em sociedade, consciente ou inconscientemente, sempre utiliza formas de representação para se mostrar a seus semelhantes, empregando certas técnicas para a sustentação de seu desempenho, tal qual um ator que representa um personagem diante do público. A perspectiva que emprega é a da representação teatral, com base nos princípios dramatúrgicos. Para ele, a vida apresenta coisas reais e, às vezes, bem ensaiadas. A diferença está no fato de que:

(...) no palco um ator se apresenta sob a máscara de um personagem para personagens projetados por outros atores. A platéia constitui um terceiro elemento da correlação. Elemento que é essencial, e que entretanto, se a representação fosse real, não estaria lá. $\mathrm{Na}$ vida real, os três elementos ficam reduzidos a dois: o papel que um indivíduo desempenha é talhado de acordo com os papéis desempenhados pelos outros presentes e, ainda, esses outros também constituem a platéia (GOFFMAN, 1999, p. 9)

Como vemos, os princípios da psicologia social traçados por E. Goffman dizem respeito a uma situação "real", isto é, face to face. Estas noções, entretanto, serão empregadas na análise de um produto cultural o cinema documentário, no caso, o filme Edifício Máster, de Eduardo Coutinho -, o que nos ajudará a entender a maneira pela qual o ator social se apresenta a si mesmo diante da câmera e do cineasta, os meios pelos quais dirige e regula a impressão que formam a seu respeito e, ao mesmo tempo, como o cineasta se utiliza dessa "atuação" para criar a sua própria representação - o filme -, articulando nesse momento a interação com o espectador. A tarefa do cineasta parece ser então a de captar objetivamente a subjetividade do outro para exercer a sua.

Logo, o que vai distinguir a relação que se mantém entre uma pessoa na presença de outras e o documentário é o fato de haver a situação face to face, em parte, no momento em que o ator social se encontra na presença do cineasta e sua equipe de produção, não existindo, entretanto, essa interação direta com o espectador. Todavia, os personagens sabem que serão vistos por um grande número de outras pessoas, o que é representado pela câmera, que por si só já interfere no real cotidiano desses personagens. No documentário, então, os três elementos presentes na atuação teatral voltam a se encontrar: ator social x cineasta/câmera x espectador (platéia).

O filme documentário é, hoje, considerado pela maioria dos cineastas e teóricos não como simples reprodução do real, mas, sobretudo, como forma de representação. O teórico Bill Nichols, por exemplo, considera que: "todo filme é um documentário" (NICHOLS, 2005: 26). Ele entende que qualquer filme mostra a cultura que o produziu e representa a aparência das pessoas que participam do filme, sejam elas atores profissionais ou não. Assim, considera o documentário como uma representação do mundo "real", a partir de um determinado ponto de vista de quem o produziu.

Por isso, classifica a ficção como "documentário de satisfação de desejos", evidenciando que este tipo de filme está preocupado com o universo onírico. A não-ficção, por sua vez, é classificada como "documentário de representação social", e como tal exige maior responsabilidade do cineasta, tanto para com o universo representado como para o público a que é destinado. É um tipo de filme que proporciona uma troca de experiência direta e reflexões acerca do mundo que não é só dos atores sociais, mas do próprio espectador.

A partir destes pressupostos, tentaremos entender, através da análise de Edifício Master, o que acontece quando um cineasta e sua equipe se encontram com uma pessoa sob a mediação da câmera e o que eles fazem com esta relação "capturada". 


\section{Uma breve apresentação: Edifício Master}

Edifício Master, de Eduardo Coutinho, surgiu, inicialmente, de uma idéia da pesquisadora Consuelo Lins, de realizar um filme em um prédio no bairro do Leme, no Rio de Janeiro. Com a idéia aceita, Coutinho encontrou em João Moreira Salles e na Videofilmes o apoio para produzir o seu documentário, mas foi Eliska Altman (amiga do diretor) quem propôs que o edifício fosse o Master, localizado em Copacabana, prédio para o qual ela havia se mudado havia pouco tempo e onde Coutinho havia morado nos anos 60. Trata-se de um prédio que tinha uma história, um passado condenável, e buscava uma transformação: tornar-se um prédio "familiar". O Master tem 12 andares, com 23 apartamentos por andar. Ao todo, são 276 apartamentos conjugados.

Conforme Lins (2004) descreve em seu livro O documentário de Eduardo Coutinho: televisão, cinema e vídeo, o que mais empolgou o cineasta neste projeto foi acreditar que "o espectador teria possibilidades de sobra para estabelecer ligações entre a vida que iria encontrar ali e a condição geral das camadas médias mais modestas da população brasileira" (LINS, 2004: 140).

Antes de começar a filmagem propriamente dita, a equipe de produção realizou uma pesquisa para confirmar ou não a viabilidade do trabalho. Para tanto, realizaram uma espécie de "etnografia", a partir da observação participante. Alugaram o apartamento 608 no Edifício Master, em julho de 2001. A equipe era composta por cinco pesquisadores, que colocaram um aviso na portaria do edifício informando sobre as três semanas de pesquisa. Com o auxílio do síndico e do porteiro, foi passada uma lista entre os moradores que eles consideravam mais interessantes. A partir daí, a equipe fez um mapa com os números dos apartamentos e dividiu os andares entre duas equipes para começar as visitas.

As primeiras semanas foram cheias de pessimismo, por medo de que o filme não fosse realizado, isso porque o material coletado nas visitas parecia não render um filme; todavia, aos poucos, percebeu-se nas dificuldades o que realmente interessava, os modos de vida das pessoas, a diversidade de experiências e "uma outra forma de estar no mundo, um modo de preservação desenvolvido por homens e mulheres de um prédio de Copacabana para sobreviver na cidade" (LINS, 2004: 146).

O documentário Edifício Master, que inicialmente se chamaria Copacabana 2001, foi então editado e exibido em 110 minutos, padrão estabelecido muitas vezes pelos filmes de longa-metragem, e conta a história a partir de entrevistas feitas com moradores de classe média de um prédio carioca, em Copacabana.

O que parece mais interessante é que o bairro não aparece em nenhuma imagem de rua, lojas ou calçadas, ele é identificado pelas alusões dos entrevistados aos assaltos, fobias, multidões e até mesmo ao comércio sexual. Por isso mesmo, mostra a claustrofobia não só por parte dos depoentes, mas das próprias imagens sempre muito fechadas, como se o espaço físico fosse insuficiente para comportar tanta gente.

A técnica utilizada por Coutinho foi a da câmera de vídeo, pois, como queria o seu filme construído por entrevistas, percebeu que a película, cuja fita dura 11 minutos e o som, 15, poderia "quebrar" a espontaneidade do entrevistado. Através de sua famosa técnica de entrevista interativa, o cineasta dialogou com 37 moradores, conseguindo histórias íntimas e reveladoras.

O documentário foi, então, dirigido por Eduardo Coutinho e contou com Cristina Grumbach como assistente de direção, Jaccques Cheuiche como diretor de fotografia e câmera, Valéria Ferro, responsável pelo som direto, Jordana Berg pela montagem, Consuelo Lins, Cristina Grumbach, Daniel Coutinho, Eliska Altman e Geraldo Pereira pelas pesquisas, Beth Formaggini pela direção da produção, Mauricio Andrade Ramos e João Moreira Salles pela produção executiva, a Videofilmes como produtora e a 
Riofilmes como finalizadora e distribuidora, o que comprova que um filme é carregado de valores e significados atribuídos por toda uma equipe e não apenas pelo diretor.

Além de todas estas questões, outra que chama atenção em Edifício Master é o fato de esse documentário, além de promover debates sobre as questões referentes à linguagem cinematográfica, ainda evidenciar a riqueza do homem comum e a importância de se humanizar o "outro" no processo de comunicação. O filme mostra que esse "outro", assim como o próprio entrevistador/diretor, são seres humanos cheios de angústias, medos, vaidades, remorsos, alegrias. Pessoas que se re-inventam diante da câmera e do próprio discurso. Por isso, durante uma entrevista, podemos perceber que os papéis podem se inverter e o entrevistador perder sua invulnerabilidade, sua onipotência e imparcialidade. É o processo comunicativo/ interativo que se concretiza.

\section{Edifício Master: a representação do "eu" na interação com o "outro"}

Edifício Master não é aquele tipo de documentário que narra uma história, no sentido clássico da expressão, e muito menos apresenta uma temática bem definida. Não se trata de um filme sobre a classe média-baixa carioca, bem como não é um filme sobre um dos bairros mais famosos do Brasil, Copacabana, tão cantado pela Bossa Nova, explorado pelas telenovelas da Rede Globo e pelas agências de turismo, funcionando como cartão postal da cidade do Rio de Janeiro. O documentário, antes de tudo, procura dar voz a fragmentos da vida de pessoas que tem em comum o fato de residirem no mesmo espaço, mas que se mostram bem diferentes. São histórias variadas que compõem o universo de um edifício igual a qualquer outro.

A sua intenção, portanto, não é dizer a verdade, ser histórico ou educativo, mas trazer à tona uma possível realidade fílmica, isto é, mostrar o que ocorre quando um cineasta e sua equipe se encontram com uma pessoa sob a mediação da câmera. Logo, o que o filme procura apresentar são pessoas que elaboram e reelaboram suas próprias experiências existenciais, compondo-se e recompondo-se no decorrer da interação com o cineasta.

Edifício Master elenca um cenário variado de atores do mundo real com suas próprias histórias de vida, cada um com seu drama pessoal para contar. Muitos são divertidos e encaram a vida com humor, outros se entregam às emoções e choram durante o depoimento e alguns demonstram o medo de viver em sociedade. Apesar das diferenças, todos desempenham o seu próprio papel diante da câmera. São pessoas reais que, na hora da filmagem, dão vida aos seus próprios personagens. Fazem a imagem "real" e a "virtual" se encontrarem na mesma cena.

Assim, em Edifício Master a fronteira entre ficção e realidade fica completamente indefinida. Entretanto, é importante enfatizar mais uma vez que os personagens do filme são pessoas reais e que, portanto, o fato de o documentário ser uma representação social solicita certa preocupação em relação à vida dessas pessoas que estão se representando e sendo representadas. João Moreira Salles afirma que:

Todo documentarista enfrenta dois grandes problemas, os únicos que de fato contam na profissão. O primeiro diz respeito à maneira como ele trata seus personagens; o segundo, ao modo como apresenta o tema para o espectador. O primeiro desses problemas é de natureza ética; o segundo é uma questão epistemológica (SALLES, 2004: 7)

Ao se referir à postura ética, João Moreira Salles chama a atenção para o fato de que após as filmagens as pessoas retratadas no filme dão prosseguimento à mesma vida que levavam antes de serem filmadas. Logo, qualquer passo em falso por parte da equipe de produção do documentário, que conhece a linguagem e o poder da imagem mal trabalhada, pode acarretar em grandes problemas para os atores 
sociais.

Em Edifício Master, a entrevista, ou melhor, o ato da fala, é praticamente a única forma de dramatização, nada acontece além da câmera fixa e as pessoas falando diante dela. Não há nem mesmo imagens de cobertura durante as falas. Até a passagem de um depoimento para o outro não obedece a uma sequiência lógica/ linear. Essa foi a forma encontrada por Coutinho para permitir que as pessoas falassem de si mesmas, uma expressão narrativa original provocada pela interação entre a câmera, o cineasta e o seu entrevistado. Coutinho estimula uma cena e observa como seus personagens representam a si mesmos. Estes buscam se adaptar à cena se re-inventado para câmera.

Segundo Goffman (1999), "quando uma pessoa chega à presença de outras, existe, em geral, alguma razão que a leva a atuar de forma a transmitir a elas a impressão que lhe interessa transmitir" (GOFFMAN, 1999: 13-14). É dessa maneira que, no decorrer de suas performances, estes atores sociais se tornam concomitantemente mais verdadeiros e mais falsos do que na sua normalidade cotidiana. As personagens estão sempre divagando entre o estado real e o fictício.

Alessandra, por exemplo, é o tipo de personagem que vai se re-inventando conforme o rumo da conversa, no jogo interativo com o cineasta, que se mantém receptivo às suas divagações. Ao final da conversa, ela chega ao auge de toda sua fabulação ao se assumir como uma verdadeira mentirosa.

Goffman (1999) nos esclarece o fato de o indivíduo esquematizar uma definição da situação quando se encontra na presença de outros: supõe-se que durante essa interação ocorram fatos que lancem dúvidas sobre esta esquematização. Quando isto acontece "a própria interação pode sofrer uma interrupção confusa e embaraçosa” (GOFFMAN, 1999: 20-21). É exatamente isto o que ocorre no depoimento de Alessandra, que, após relatar os acontecimentos de sua vida, seus sonhos, desejos, chega mesmo a afirmar que tudo o que disse pode ter sido inventado:

Eu sou muito mentirosa. Eu conto mentira e acho que pra gente mentir a gente tem que acreditar na mentira, pra mentira ficar bem feita. E eu sou assim. Eu sou muito mentirosa, muito mesmo. Eu até choro pra mim acreditar na minha mentira. Eu sou uma mentirosa verdadeira. Eu falo a mentira, mas eu falo a verdade (informação verbal).

Alessandra nos dá a ver uma fabulação ao mesmo tempo real e imaginária, verdadeira e falsa. Assim, as articulações da personagem são utilizadas para questionar o próprio documentário. Ao utilizar o depoimento de Alessandra para compor o seu filme, Coutinho interage com o espectador, permitindo que questionemos a veracidade do seu documentário, que é estabelecido como um jogo de cena.

Esta pode também ter sido uma das estratégias utilizadas por Alessandra, o que Goffman chama de "prática defensiva", ou seja, quando um indivíduo tenta proteger suas próprias projeções. Alessandra lança a dúvida e não a esclarece, salvaguardando a sua própria intimidade.

Outra personagem que se utiliza dessa estratégia é Maria do Céu, uma das moradoras mais antigas do prédio, que se lembra da época em que o Master era um "antro de perdição". Seu depoimento é alegre, cheio de gargalhadas e encenações de situações que ela presenciou no passado: as brigas nos corredores, o tráfico, a prostituição sexual, bebedeiras na portaria. Ao mesmo tempo em que fala, Maria do Céu se levanta da poltrona, gesticula e confessa que era tudo muito divertido. Em seguida, como se estivesse arrependida, volta atrás, muda o tom de voz e elogia o síndico e as mudanças feitas por ele para que o prédio se tornasse um ambiente "familiar": "agora está melhor" (informação verbal).

Goffman (1999) afirma que quando realizamos a representação de nós mesmos para o outro, sempre 
tentamos parecer melhores do que somos, é o princípio da idealização que se efetiva: “(...) um ator cuida de dissimular ou desprezar as atividades, fatos e motivos incompatíveis com a versão idealizada de sua pessoa e de suas realizações" (GOFFMAN, 1999: 51). É, portanto, sob este princípio que a personagem Maria do Céu age ao "voltar atrás" e concordar com a ordem imposta pelo novo síndico, tentando salvaguardar a sua imagem como uma senhora de família, imagem esta que é bem aceita pela nossa sociedade.

Coutinho, destarte, permite que seus personagens se contradigam, trazendo à tona o conflito interno do ser humano e explicitando mais uma vez a função deflagradora da câmera neste encontro fílmico. $\mathrm{O}$ casal, Carlos e Maria Regina, por exemplo, lavam a "roupa suja" em frente às câmeras, falam da dificuldade do relacionamento, do amor que se encerra. Maria Regina age de modo irônico, sorri de soslaio, revira os olhos para discordar das colocações do marido. Carlos se mantém sério e escuta mais do que fala, explicando as desavenças do relacionamento como consequiências dos ciúmes da esposa. Ao final da conversa, no entanto, estão abraçados e de mãos dadas. Terminam a narração dizendo: "nós não prestamos, mas nos amamos" (informação verbal).

Aqui presenciamos o que Goffman (1999) chama de "fachada pessoal", aquilo que se refere aos itens de equipamento expressivo que são inerentes ao próprio ator social. A "fachada pessoal" inclui tanto os itens fixos como sexo, idade, raça, etc. como os transitórios a exemplo da expressão facial, que pode variar, numa representação, de um momento a outro (GOFFMAN, 1999: 31).

Além do casal que se contradiz em seu relato, outros personagens se articulam da mesma forma; é o caso do senhor que se diz tímido e que por isso corre o risco de gaguejar e estragar a entrevista, mas conta sua história de uma vez e ainda se emociona. Alessandra, por sua vez, não só lança a dúvida quanto à credibilidade do seu depoimento e do próprio documentário como, mais uma vez, se contradiz durante a conversa: "esse mundo aqui é muito ruim, eu sofro muito, quando eu morrer serei feliz, mas eu não quero morrer não, não quero mesmo" (informação verbal).

E. Goffman (1999) constata ainda que numa representação o ator social pode se valer de recursos na tentativa de isolar sua personalidade íntima do contato com o público. Em Edifício Master, a professora de inglês, Daniela, é uma delas. A todo tempo evita encarar a câmera e o próprio cineasta. Apresenta-se sempre de perfil, ora olhando para os lados, ora para o chão e assume ser uma pessoa neurótica e sociofóbica, não suportando a multidão de gente em Copacabana. Daniela cria uma série de encenações que vão desde o olhar ao tom de voz. Ela pisca os olhos quando relata o motivo de não encarar o olhar do cineasta e da própria câmera, é enfática ao dizer que não deve, mas teme a presença de Coutinho e vai criando seus personagens, que se desdobram em vários outros.

Muitos personagens também tentam simular a sua realidade, no momento da entrevista, através da apresentação de uma casa impecável no que se refere à limpeza e à arrumação, alguns dão prioridade às vestimentas e outros a uma recepção com direito a um "lanchinho". Todos se utilizam do que Goffman (1999) chama de "cenário", uma das partes da "fachada", que vai contribuir para o desenrolar da ação humana. Nesse sentido, "O inferior pode estar tentando, com muito tato, colocar o superior à vontade, simulando o tipo de mundo que se julga que o superior considera natural" (GOFFMAN, 1999: 27). Os atores procuram tornar natural o espaço que imaginam que o cineasta esteja esperando.

É interessante notar que em Edifício Master não só os atores sociais são personagens, mas o próprio diretor e sua equipe representam seus próprios papéis sociais de cineasta e equipe de produção ao aparecerem no filme, colocando em evidência o enigma da "verdade" nas interações sociais cotidianas que são recheadas por encenações, ao mesmo tempo em que nos levam à reflexão de que todo o processo apresentado pelo documentário é criado pelo e para o filme, sendo esta uma das únicas e possíveis 
“verdades" alcançáveis - o acontecimento fílmico em si.

Este é um procedimento denominado por Bill Nichols (2005) como "modo reflexivo", aquele que permite que o documentário utilize-se da metalinguagem, falando não só do mundo histórico, mas também dos problemas e questões da representação, a partir do próprio documentário, como ele mesmo nos mostra:

O modo reflexivo é o modo de representação mais consciente de si mesmo e aquele que mais se questiona. $\mathrm{O}$ acesso realista ao mundo, a capacidade de proporcionar indícios convincentes, a possibilidade de prova incontestável, o vínculo indexador e solene entre imagem indexadora e o que ela representa - todas essas idéias passam a ser suspeitas. (NICHOLS, 2005: 166).

Esta técnica antiilusionista começou a entrar em vigor por volta dos anos 70 e vem ganhando força na atualidade. É uma forma que os documentaristas encontraram para mostrar a obra como produto, desvendando o processo de produção. O modo reflexivo procura ressaltar o que antes estava implícito e o cineasta se assume como produtor de significados, criando discursos cinematográficos. "(...) os documentários reflexivos pedem-nos para ver o documentário pelo que ele é: um construto ou representação" (NICHOLS, 2005: 163).

Com Edifício Master nos perguntamos, então, como Coutinho se articula para fabricar a sua narrativa, quais os recursos utilizados, de que forma se propõe a retratar os fatos, dramatizando a cena ou apenas capturando o que acontece diante de seus olhos.

O filme tem início com a equipe de produção e filmagem adentrando o prédio, o que é visto a partir das imagens de uma câmera de vigilância do edifício. O fato de mostrar ao público o que geralmente é omitido já traz embutido na própria narrativa a idéia de que o filme nada mais é do que escolhas e seleções de fatos e cenas. Como nos mostra Lins (2004): "há uma retomada do procedimento de que estamos assistindo não ao "real" propriamente, mas ao encontro de uma equipe de cinema com um determinado universo, este já surge envolto na imagem de uma câmera de vigilância" (LINS, 2004: 153).

Em algumas cenas que intercalam as entrevistas, as imagens das câmeras de vigilância tornam a aparecer, expondo as escolhas dos apartamentos a serem filmados, o deslocamento da equipe pelo edifício, as cenas internas do elevador, o que demonstra uma espécie de "invasão admitida" tanto pelo prédio, quanto pela equipe de produção.

Outra leitura possível da câmera de vigilância que não anula a idéia anterior é encará-la como dispositivo disciplinar, de controle. Estamos neste momento nos referindo ao conceito de "panóptico" (2), de Jeremy Benthan, utilizado por Foucault para defender a idéia de que a vigilância e a punição são formas do sistema de ortopedia social que se instaura para o controle da sociedade. São formas de poderes destinados a educar e adestrar as pessoas para que essas cumpram normas e leis. É uma forma mais eficaz de supervisionar do que punir.

Quanto ao Master, este, segundo os próprios depoentes, até pouco tempo atrás havia sido um "antro de perdição", ali conviviam prostitutas, traficantes, travestis. Voltou a ser um prédio "familiar" com a administração do novo síndico, que adquiriu a câmera de vigilância. Conforme ele mesmo diz: "Queria colocar o prédio bonito, digno, decente, isso graças a Deus eu consegui" (informação verbal). A câmera passou então a funcionar como dispositivo de controle da vida social do edifício que se "moralizou". O fato de a equipe de produção aparecer traz também a idéia do circuito fechado, da vigilância pública.

A preocupação de Coutinho parece ser, deste modo, tentar fazer um filme com os atores sociais e não sobre eles. Sua autoria se mistura à dimensão autoral dos próprios personagens que agem 
espontaneamente. Temos, então, a possibilidade de criação de algo inesperado no momento da filmagem. Nesse caso,

O "eu”, portanto, como um personagem representado, não é uma coisa orgânica, que tem uma localização definida, cujo destino fundamental é nascer, crescer e morrer; é um efeito dramático, que surge difusamente de uma cena apresentada, e a questão característica, o interesse primordial, está em saber se será acreditado ou desacreditado (GOFFMAN, 1999, p. 231).

No filme, no entanto, não interessa acreditar ou desacreditar daquilo que é real ou fictício. Edifício Master nos mostra que essa dúvida faz parte da própria realidade que é composta, também, pela falsidade.

\section{Considerações finais}

A partir da análise feita, podemos perceber que mais do que mostrar como as pessoas são, em Edifício Master fica evidente o quanto elas podem ser múltiplas, se permitindo representar diferentes personagens de si mesmas, sempre cruzando as fronteiras entre a realidade e a ficção, o verdadeiro e o falso. Como nos mostra Goffman (1999): “(...) a própria vida é uma encenação dramática. O mundo todo não constitui evidentemente um palco, mas não é fácil especificar os aspectos essenciais em que não é" (GOFFMAN, 1999: 71). O momento da filmagem cria, portanto, uma nova realidade, transformando os depoimentos dos atores sociais em relatos de um novo fato - a realidade fílmica.

Para tanto, alguns recursos foram necessários à viabilização de um diálogo de longa duração do cineasta com os personagens selecionados, para proporcionar uma fala espontânea, um gesto imprevisto, uma "revelação", a saber, a locação única para restringir o espaço do filme a um único universo, no caso o edifício Master, o uso de equipamentos de vídeo em vez de película cinematográfica na filmagem e a escolha do plano quase sempre fixo, com a câmera no tripé.

A presença do cineasta, sua câmera e a equipe de produção diante de uma pessoa comum disparam um movimento que não estava presente no real cotidiano dessas pessoas, o que cria o "acontecimento fílmico" em si. O filme proporciona, então, a reflexão sobre a impossibilidade de se filmar o real, que está em constante transformação. O que se filma é a interação, pois mesmo quando se tem como objetivo a verdade dos fatos, a presença da câmera já interfere no real, por isso é que, "para muitos acontecimentos sociológicos pode nem mesmo ser necessário decidir qual a mais real, se a impressão criada ou a que o ator tenta impedir que o público receba" (GOFFMAN, 1999: 66).

A composição do filme com os personagens se revelando diante da câmera nos dá a ver a fragmentação e os paradoxos do homem moderno: a solidão em meio ao caos urbano, a negação daquilo em que realmente acredita, no intuito de salvaguardar a sua sociabilidade, etc. $\mathrm{O}$ depoimento final é o de uma garota que afirma que não se imagina, na verdade, em nada, relato que finaliza a própria idéia do filme, a de que é impossível concluir a vida de um personagem, uma história e o próprio documentário.

\section{Bibliografia:}

DA-RIN, S. Espelho Partido: Tradição e transformação do documentário. São Paulo: Azougue, 2004.

FOUCAULT, M. Vigiar e punir: nascimento da prisão.Trad. Lígia Pondé Vassallo. Petrópolis, RJ: Vozes, 2001. 
GOFFMAN, E. A representação do eu na vida cotidiana. Trad. Maria Célia Santos Raposo. 8.ed. Petropolis, RJ: Vozes, 1999.

LINS, C. O documentário de Eduardo Coutinho: televisão, cinema e vídeo. Rio de Janeiro: J. Zahar, 2004.

NICHOLS, B. Introdução ao documentário. Trad. Mônica Saddy Martins. Campinas: Papirus, 2005.

A voz do documentário. Trad. Eliana Rocha Vieira. In: RAMOS, F. P. (org.). Teoria Contemporânea do Cinema: documentário e narratividade ficcional. São Paulo: Ed. SENAC/SP, 2005. p. 47-67.

SALLES, J. M. Prefácio. In: DA-RIN, S. Espelho Partido: tradição e transformação do documentário. Rio de Janeiro: Azougue Editorial, 2004. p. 7-12.

\section{Filmografia:}

Edifício Master. Direção: Eduardo Coutinho. Produção: Videofilmes. Rio de Janeiro, 2002. Dur. 110 min. 1 DVD.

\section{Notas:}

(1) Artigo apresentado no V ENECULT - Quinto Encontro de Estudos Multidisciplinares em Cultura, na Universidade Federal da Bahia - UFBA/ Salvador-BA.

(2) O "panóptico" refere-se à construção prisional proposta em 1791 pelo filósofo utilitarista Jeremy Benthan, que propõe uma construção semicircular dividida em células. Cada uma das células torna o prisioneiro visível a partir de uma rótula central. Os prisioneiros não podem saber, em contrapartida, se são ou não observados.

\section{Mini Currículo :}

Marine Souto Alves é mestranda e bolsista CAPES do curso de Letras: Linguagens e Representações pela Universidade Estadual de Santa Cruz - UESC, sob a orientação do Prof ${ }^{\circ}$ Dr. Cláudio do Carmo Gonçalves. Graduada em Comunicação Social com habilitação em Rádio e TV pela Universidade Estadual de Santa Cruz - UESC (2008).

Cláudio do Carmo Gonçalves é doutor em Ciência da Literatura pela UFRJ; Docente do Mestrado em Letras junto ao Programa de Pós-Graduação em Linguagem e representações e Adjunto do Departamento de Letras e Artes da Universidade Estadual de Santa Cruz/ UESC - Bahia. Graduado em Letras pela UERJ / UniverCidade ; Museologia pela UNI-RIO; Direito pela Metodista Bennett; Mestre em Ciência da Literatura pela UFRJ ; Produção acadêmica e pesquisas nas áreas de memória, com ênfase nos tópicos de Patrimônio, crítica da cultura, cânone e ficção contemporânea. 